\title{
QUALIDADE PÓS-COLHEITA DA CAJARANA EM DIFERENTES ESTÁDIOS DE MATURAÇÃO DURANTE ARMAZENAMENTO REFRIGERADO ${ }^{1}$
}

\author{
EDNA MARIA MENDES AROUCHA ${ }^{2}$, CLARICE SALES MORAES DE SOUZA ${ }^{3}$ \\ ALINE ELLEN DUARTE DE SOUZA ${ }^{4}$, RAFAELLA MARTINS DE ARAÚJO FERREIRA ${ }^{5}$ \\ JOSÉ CARLOS AROUCHA FILHO ${ }^{6}$
}

RESUMO - Este trabalho objetivou avaliar a qualidade pós-colheita da cajarana em diferentes estádios de maturação, durante armazenamento refrigerado. Os frutos foram coletados no município de Mossoró/ $\mathrm{RN}$, em quatro estádios de maturação (I: frutos verdes, com algumas protuberâncias; II: frutos com 75\% da casca verde; III: frutos com $50 \%$ da casca verde; IV: frutos com $25 \%$ de casca verde) e transportados para o Laboratório de Pós-Colheita da UFERSA, onde foram selecionados quanto à uniformidade de maturação, lavados e colocados em bandeja plástica para o transporte até a câmara fria regulada com temperatura de $10 \pm 2{ }^{\circ} \mathrm{C}$ e UR $90 \pm 5 \%$, onde permaneceram por sete e 14 dias. Os frutos foram avaliados quanto à perda de massa, teor de sólidos solúveis, acidez titulável e vitamina C. O delineamento experimental utilizado foi o inteiramente casualizado, em esquema fatorial $4 \times 2$. Para a comparação entre temperaturas, utilizou-se o teste de Tukey, ao nível de 5\% de probabilidade, e para os períodos de armazenamento utilizaram-se os modelos de ajustamentos da regressão simples. Verificou-se que as características dos frutos foram conservadas, independentemente do estádio de maturação, até sete dias de armazenamento refrigerado. Aos 14 dias de armazenamento, os frutos colhidos no estádio II de maturação, mantiveram boa qualidade, enquanto os frutos no estádio de maturação I não desenvolveram as características típicas do fruto maduro e aqueles colhidos no estádio III e IV manifestaram sintomas de senescência.

Termos para indexação: Spondias cytherea. Análises fisico-químicas. Fruto tropical.

\section{POSTHARVEST QUALITY OF AMBARELLA AT DIFFERENT STAGES OF MATURATION IN COLD STORAGE}

\begin{abstract}
This study aimed to evaluate the postharvest quality of ambarella at different stages of maturation in cold storage. The fruits were collected in Mossoró, $\mathrm{RN}$, at four ripening stages (I: green fruit, with some lumps; II: fruit with $75 \%$ green skin; III: fruit with $50 \%$ green skin; IV: fruit with $25 \%$ of green skin) and transported to the Laboratory of Post-Harvest at UFERSA, where they were selected for uniformity of ripeness, washed and placed on a tray for transport to the cold-regulated temperature of $10 \pm 2{ }^{\circ} \mathrm{C}$ and RH $90 \pm 5 \%$, where they remained for seven and 14 days. Fruits were evaluated for weight loss, soluble solids, acidity and vitamin $\mathrm{C}$. The experimental design was completely randomized in a $4 \times 2$ factorial. To compare temperatures, it was used the $\mathrm{F}$ test at $5 \%$ probability and for the storage periods it was used the adjustment models of simple regression. It was found that the fruit characteristics were preserved, regardless of maturity stage, up to seven days of refrigerated storage. At 14 days of storage, the fruits harvested at stage II of maturity, maintained good quality. While the fruit at maturity stage I have not developed the typical features of ripe fruit and those harvested at III and IV showed symptoms of senescence.
\end{abstract}

Index terms: Spondias cytherea, Physiochemical analyses, Tropical fruit.

\footnotetext{
${ }^{1}$ (Trabalho 193-11). Recebido para publicação em: 04-07-2011. Aceito para publicação em: 14-04-2012.

${ }^{2}$ Dra. em Produção Vegetal - Professora Adjunta IV da Universidade Federal Rural do Semi-Árido. E-mail: aroucha@ufersa.edu.br ${ }^{3}$ Eng. Agronoma - Mestranda em Desenvolvimento e Meio Ambiente pela Universidade Federal do Rio Grande do Norte. E-mail: clarice_agro@hottmail.com

${ }^{4}$ Ms. em Fitotecnia - Doutoranda em Fisiologia Vegetal pela Universidade Federal de Viçosa. E-mail: aline_esam@hotmail.com ${ }^{5}$ Eng. Agronoma - Doutoranda em Fitotecnia pela Universidade Federal Rural do Semi-Árido. E-mail: rafaellamarafe@gmail.com ${ }^{6}$ Engenheiro Florestal, Universidade Federal Rural do Pará e-mail-carlosaroucha@yahoo.com.br
} 


\section{INTRODUÇÃO}

O gênero Spondias pertencente à familia das Anacardiaceas compreende cerca de 17 espécies (MILLER;SCHAAL, 2005), dentre as quais podemos destacar: cajarana (Spondias cytherea), cajá ( $S$. lutea), ciriguela (S. purpurea) e umbu (S. tuberosa), que são exploradas de forma extrativista em várias áreas tropicais e subtropicais do mundo.

As Spondias têm importância econômica, principalmente pelas características típicas de seus frutos (CARVALHO et al., 2008), constituindo-se uma fonte suplementar de renda para muitas famílias do semiárido brasileiro (SOUZA et al., 2005; SILVA; AMORIM, 2009). Porém, existem poucas informações quanto à conservação pós-colheita e aos aspectos socioeconômicos das espécies existentes no Brasil.

Os frutos in natura têm participação crescente no agronegócio da região Nordeste devido ao sabor exótico e excelente qualidade, possuindo boa aceitação no mercado como matéria-prima no preparo de sucos, picolés, sorvetes, néctares, geleias, e principalmente de polpa congelada. (SOARES et al., 2006; MATTIETTO et al., 2007; CARVALHO et al., 2008).

A cajarana é um fruto climatérico e seu processo de maturação pode ser dividido em cinco estádios distintos de acordo com as características físicas e químicas (MEDEIROS, 2005), são altamente perecíveis, e por isso, atualmente, são explorados principalmente na forma processada (MATA et al., 2005).

Sampaio et al. (2007) observaram, após 186 horas da colheita, através do monitoramento do processo respiratório de frutos de cajá, a liberação máxima de $\mathrm{CO}_{2}$ de $54,2 \mathrm{~mL} \cdot \mathrm{kg}^{-1} \cdot \mathrm{h}^{-1}$, quando o fruto alcançou qualidade máxima, iniciando em seguida a senescência. Isto resultou em uma vida útil de prateleira dos frutos de apenas 8 dias.

A cadeia de frio é uma técnica eficiente utilizada no prolongamento da vida útil de frutas frescas, que consiste na manipulação dos produtos em temperatura ideal, desde o paking house até a gôndola do supermercado. De acordo com Silva (2008), uma das maiores dificuldades enfrentadas pelas empresas é a manutenção da cadeia de frio para a conservação da qualidade das frutas até o consumidor final.

O estádio de maturação adequado dos frutos, no momento da colheita, e a temperatura de armazenamento refrigerado determinam o potencial de conservação pós-colheita, sendo uma das técnicas mais importantes utilizadas no prolongamento da vida útil de produtos frescos (DREHMER; AMA-
RANTE, 2008; MACIEL et al., 2008).

$\mathrm{O}$ armazenamento em temperaturas subcríticas provoca chilling injury ou danos de frio, como: modificação da cor, que pode ser tanto interna como externa, e, usualmente, varia de marrom a preto; ocorrência de manchas aprofundadas na casca; amadurecimento irregular, ocasionando coloração anormal ou desuniforme, caracterizada pela perda do sabor e aroma do fruto, e aumento na taxa de deterioração (CHITARRA;CHITARRA, 2005).

Martins et al. (2003) detectaram em ciriguela que o estádio de maturação "amarelo predominante" e a temperatura de $9,5^{\circ} \mathrm{C}$ são as condições mais adequadas para o prolongamento de sua vida útil, sendo esta temperatura a mínima na qual os frutos podem ser armazenadas sem risco de danos pelo frio.

Tendo em vista a falta de informações sobre as características físico-químicas da cajarana e a influência do frio no prolongamento de sua vida útil, este trabalho teve por finalidade avaliar a qualidade pós-colheita da cajarana em diferentes estádios de maturação durante armazenamento refrigerado.

\section{MATERIAL E MÉTODOS}

Os frutos foram coletados em março de 2009 no município de Mossoró-RN, à latitude sul de $5^{\circ}$ $11^{\prime}$ e longitude oeste de $37^{\circ} 20^{\prime}$, e altitude de $18 \mathrm{~m}$. O clima da região, de acordo com a classificação de Köeppen, é do tipo BSwh', ou seja , quente e seco, com precipitação pluviométrica bastante irregular, média anual de $673,9 \mathrm{~mm}$, temperatura de $27^{\circ} \mathrm{C}$ e umidade relativa do ar média de 68,9\% (CARMO FILHO; OLIVEIRA, 1995).

Para o experimento, foram coletados 500 frutos em quatro estádios de maturação (I: frutos verdes, com algumas protuberâncias; II: frutos com $75 \%$ da casca verde; III: frutos com $50 \%$ da casca verde, e IV: frutos com $25 \%$ da casca verde). Após a colheita, os frutos foram transportados em monoblocos para o Laboratório de Pós-Colheita do Departamento de Agrotecnologia e Ciências Sociais (DACS) da Universidade Federal Rural do Semiárido (UFERSA), onde foram previamente selecionados e separados quanto à uniformidade de maturação. Em seguida, foram lavados em solução de hipoclorito de sódio a 100 ppm, enxugados, colocados em bandeja plástica e transportados para a câmara fria regulada com temperatura a $10 \pm 1{ }^{\circ} \mathrm{C}$ e UR $90 \pm 2 \%$, onde permaneceram durante 7 e 14 dias.

Foram realizadas as seguintes análises físicoquímicas nos frutos:

Perda de massa fresca - por diferença entre o peso inicial e o peso a cada intervalo de tempo, os 
resultados foram expressos em porcentagem (\%).

Aparência externa - avaliada através de escala subjetiva de notas proposta por Lima et al. (2007), em que: $4=$ fruta isenta de manchas e com aparência fresca; $3=$ sinais de murcha inicial (perda de brilho e turgor) e/ou presença de manchas em até $5 \%$ da superfície da fruta; $2=$ manchas em 6 a $20 \%$ da superfície e/ou enrugamento inicial; $1=$ manchas em 21 a $40 \%$ da fruta e/ou avanço do enrugamento (intensidade moderada), e $0=$ manchas em mais de $40 \%$ da área da fruta e/ou enrugamento em intensidade severa e/ou podridão.

Sólidos solúveis (SS) - através do refratômetro digital modelo PR-100 Palette (Attago Co. Ltd, Japan), e os resultados expressos em porcentagem (\%).

Acidez titulável - determinada através da titulação de uma alíquota de $10 \mathrm{~g}$ de polpa homogeneizada, com solução de $\mathrm{NaOH}(0,1 \mathrm{~N})$, previamente padronizada, com os resultados expressos em $\mathrm{mg}$ de ácido cítrico/100g de polpa.

Razão SS/AT - obtida pela razão entre o teor de sólidos solúveis e a acidez titulável; ácido ascórbico - determinado por titulometria de neutralização, e os resultados expressos em mg de ácido ascórbico/ $100 \mathrm{~g}$ de polpa.

O delineamento experimental utilizado foi o inteiramente casualizado, em esquema fatorial $4 \times 2$, consistindo em quatro estádios de maturação e dois períodos de armazenamento, com quatro repetições. Os dados foram submetidos à análise de variância, utilizando-se do software SISVAR (FERREIRA, 2003). Os níveis do fator quantitativo (estádios de maturação) foram comparados pelo teste de Tukey, ao nível de $5 \%$ de probabilidade, enquanto para os níveis do fator qualitativo (período de armazenamento) procedeu-se ao ajustamento a modelos de regressão.

\section{RESULTADOS E DISCUSSÃO}

Houve interação significativa entre os fatores estudados (estádios de maturação e período de armazenamento) apenas para as características perda de massa (Figura 1), aparência externa (Figura 2), teor de sólidos solúveis (Figura 3) e relação SS/AT (Figura 4). Observou-se ainda efeito isolado para o fator tempo nas características acidez titulável (Figura 5) e vitamina C (Figura 6) e efeito isolado para o fator estádios de maturação apenas para a acidez titulável (Tabela 1).

Verificou-se aumento significativo da perda de massa fresca dos frutos com o período de armazenamento, independentemente do estádio de maturação; sendo superior aos 14 dias de armazenamento (Figura 1). Os frutos no estádio de maturação IV apresentaram perda de massa superior aos demais estádios de maturação, aos 14 dias de armazenamento, alcançando valor superior a $20 \%$ (Figura 1), o suficiente para comprometer a aparência dos frutos, uma vez que se apresentaram mais enrugados quando comparados aos frutos nos demais estádios de maturação. Esse comportamento ocorreu, possivelmente, por esses frutos se encontrarem na fase final do amadurecimento, em que os processos degradativos superam os de síntese.

A perda de massa fresca propicia danos econômicos significativos não somente na quantidade comercializada, mas também na qualidade a ser comercializada. Chitarra e Chitarra (2005) argumentam que alguns frutos têm sua comercialização comprometida com perda de massa de apenas $4 \%$. Enquanto, outros são prejudicados efetivamente apenas com perdas de massa acima de 7\%. Neste trabalho, verificou-se que as perdas até $6,9 \%$, apresentadas pelos frutos de cajarana armazenados até sete dias, não afetaram de modo significativo a aparência dos frutos.

Com relação à aparência externa dos frutos, nota-se pouca variação nos frutos nos estádios de maturação I e II ao longo do armazenamento. Entretanto, os frutos nos estádios III e IV apresentaram significativa perda de qualidade visual ao longo do armazenamento (Figura 2). Por outro lado, observouse que, até sete dias de armazenamento, os frutos de todos os estádios obtiveram notas elevadas; entretanto, aos 14 dias de armazenamento, as notas de aparência externa mantiveram-se elevadas apenas nos frutos dos estádios I e II (Figura 2), enquanto os frutos dos estádios III e IV manifestaram sintomas de injúria pelo frio. Martins et al. (2003), trabalhando com ciriguela, detectaram que a temperatura de 9,5 ${ }^{\circ} \mathrm{C}$ é a mínima que os frutos toleram sem a ocorrência de chilling.

Levando em consideração os períodos de armazenamento em cada estádio de maturação, verifica-se acréscimo no teor de sólidos solúveis dos frutos nos estádios de maturação I e II ao longo do armazenamento (Figura 3), evidenciando, portanto, ocorrência de mudanças bioquímicas nos frutos. Graham et al. (2004) observaram aumento de sólidos solúveis em frutos de Spondias cytherea S. maturo em torno de $7 \%$ e maduro de $11 \%$.

O aumento no teor de sólidos solúveis após a colheita dos frutos está associado ao processo bioquímico de amadurecimento, principalmente nos frutos que acumulam reservas de amido, tais como ciriguela, banana e manga. Nestas espécies, ocorre a hidrólise do amido durante o amadurecimento do fruto, resultando no incremento do teor de sólidos 
solúveis.

Analisando os estádios de maturação dentro de cada período de armazenamento, pode-se observar que os frutos no estádio de maturação III e IV se sobressaíram nos teores de sólidos solúveis apenas no zero e sete dias de armazenamento. Enquanto aos 14 dias não foi observada diferenças entre os estádios de maturação para os sólidos solúveis dos frutos (Figura 3). Tal resultado pode ser explicado pelo fato de estes frutos estarem em estádio fisiológico menos desenvolvido. Bleinroth et al. (1992) explicam que os frutos em estádio de desenvolvimento fisiológico avançado apresentam vida útil pós-colheita inferior por terem ocorrido as principais mudanças bioquímicas, químicas e fisiológicas.

Houve acréscimo na relação SS/AT ao longo do armazenamento nos estádios I e II, e decréscimo nos estádios III e IV. Por outro lado, em todos os períodos de armazenamento, o estádio IV apresentou relação SS/AT superior aos demais estádios (Figura 4). Resultado semelhante foi detectado por Silva et al. (2009), ao trabalharem com estádios de maturação de frutos de cajarana, verificando incremento na relação do estádio verde para o maduro. A relação SS/AT é muito utilizada como critério subjetivo de avaliação do sabor. É interessante que essa relação apresente valores elevados, já que ela indica haver mais açúcares do que ácidos.

Pode-se observar que houve incremento na acidez titulável entre zero e sete dias de armazenamento (Figura 5), e que a concentração de ácidos orgânicos foi significativamente diferente entre os estádios de maturação (Tabela 1). Os frutos no estádio I apresentaram acidez mais elevada que os frutos dos demais estádios de maturação, enquanto a menor acidez foi observada nos frutos do estádio IV.

Resultado semelhante foi encontrado por Lima et al. (2002) ao estudarem cinco estádios de maturação de cajarana. Estes autores observaram que os frutos totalmente verdes apresentaram acidez titulável mais elevados quando comparados aos demais estádios; e, ainda, que os teores de acidez titulável são decrescentes com o aumento da maturação. Do mesmo modo, Silva et al. (2009) detectaram, em três estádios de maturação, decréscimo na acidez titulável, com o decorrer da maturação.

O teor de ácido ascórbico não foi estatisticamente diferente entre os estádios de maturação, entretanto foi significativa a diferença durante o armazenamento dos frutos. Observa-se redução no conteúdo de ácido ascórbico aos sete dias de armazenamento e, logo em seguida, incremento (Figura 6). Lopéz et al. (2004) trabalharam com ciriguela à temperatura de $20^{\circ} \mathrm{C}$ e verificaram haver decréscimo no conteúdo de vitamina $\mathrm{C}$ ao longo de armazenamento (de quatro dias), em todos os estádios de maturação. Resultados semelhantes também foram verificados por Sampaio et al. (2007), que detectaram, durante o armazenamento (de 8 dias), redução nos teores de ácido ascórbico do cajá durante o amadurecimento, e essa diferença foi significativa entre cada período de armazenamento.

TABELA 1 - Médias de acidez titulável (\% ácido cítrico) dos frutos de cajarana nos estádios de maturação I, II, III e IV submetidos a refrigeração durante o período de armazenamento. Mossoró-RN, UFERSA.

\begin{tabular}{cc}
\hline Estádios de maturação & Acidez Titulável \\
\hline I & $2,00 \mathrm{a}$ \\
II & $1,52 \mathrm{~b}$ \\
III & $1,25 \mathrm{c}$ \\
IV & $1,03 \mathrm{~d}$ \\
\hline
\end{tabular}

* Médias seguidas pela mesma letra não diferem pelo teste de Tukey, ao nível de 5\% de probabilidade. 


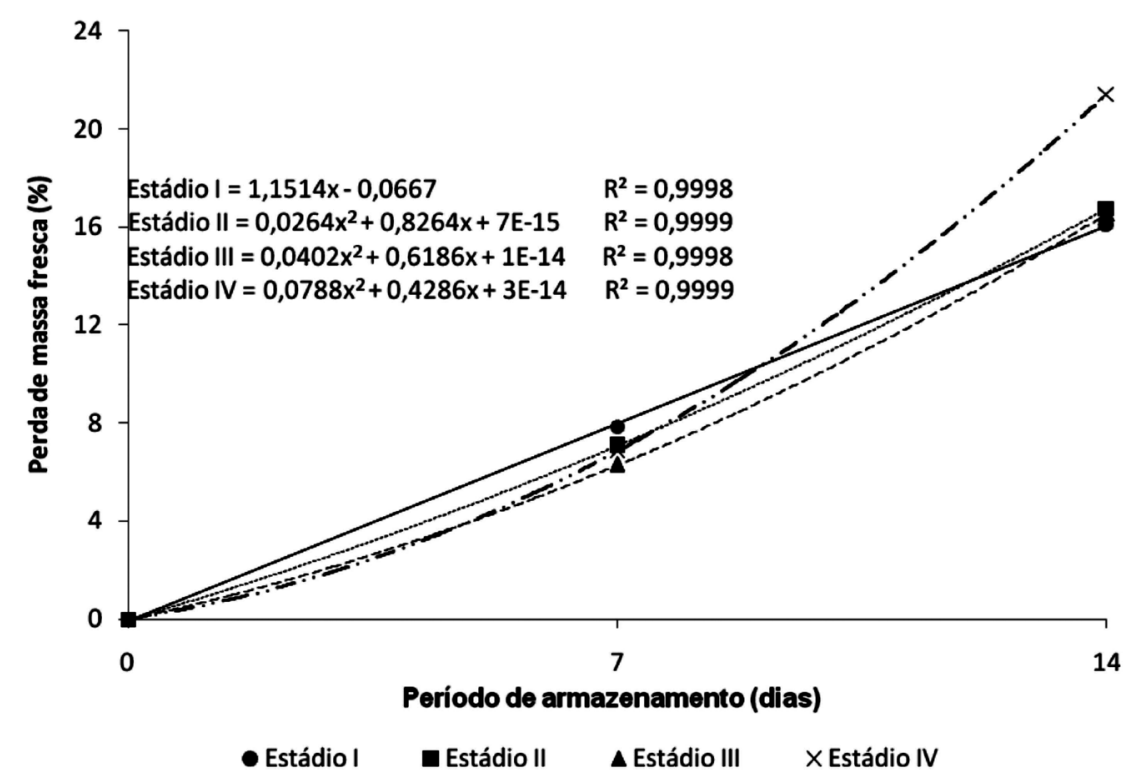

FIGURA 1 - Perda de massa fresca (\%) em frutos de cajarana nos estádios de maturação I, II, III e IV submetidos à refrigeração durante o período de armazenamento. Mossoró-RN, UFERSA.

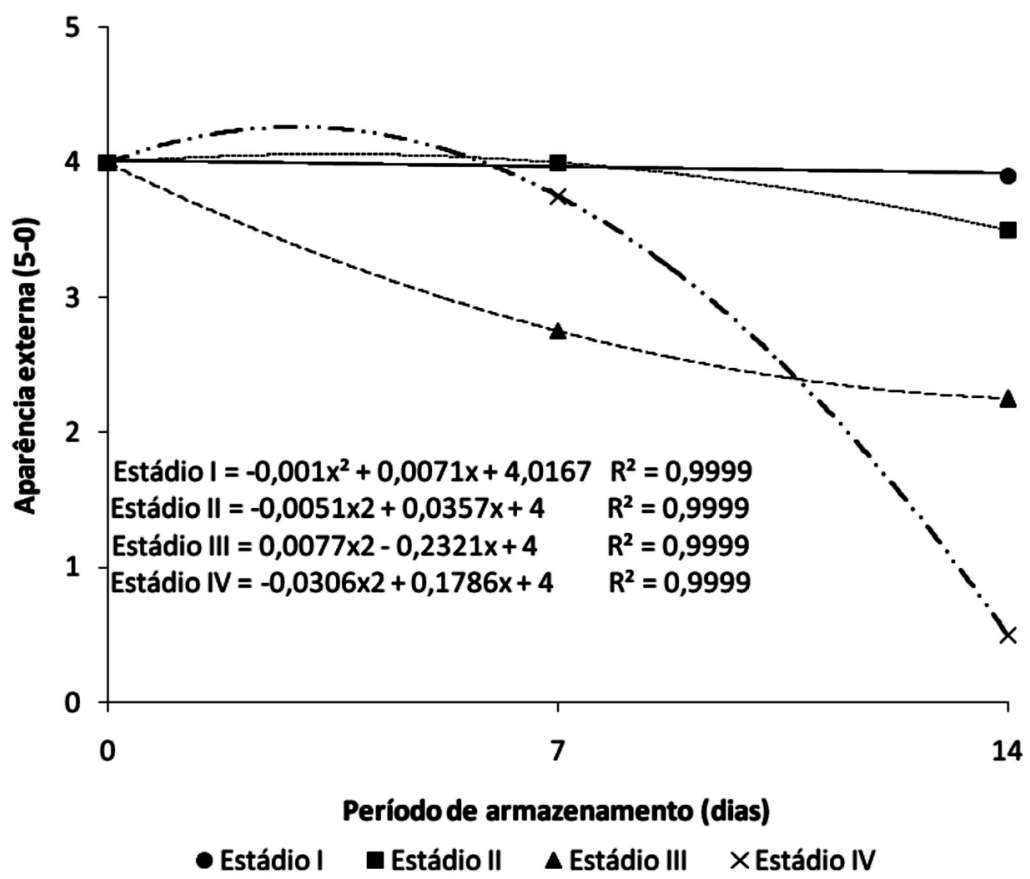

FIGURA 2 - Aparência externa de frutos de cajarana nos estádios de maturação I, II, III e IV submetidos à refrigeração durante o período de armazenamento. Mossoró-RN, UFERSA. 


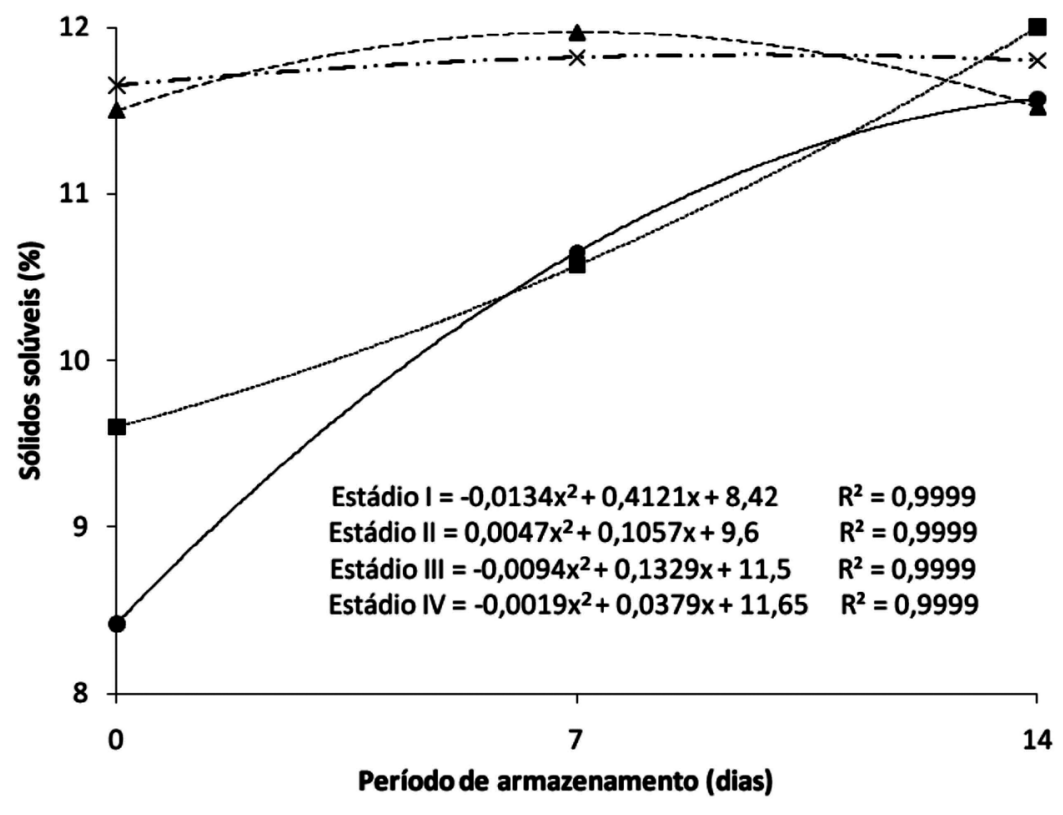

- Estádio I Estádio II $\Delta$ Estádio III XEstádio IV

FIGURA 3 - Teor de sólidos solúveis de frutos de cajarana nos estádios de maturação I, II, III e IV submetidos à refrigeração durante o período de armazenamento. Mossoró-RN, UFERSA.

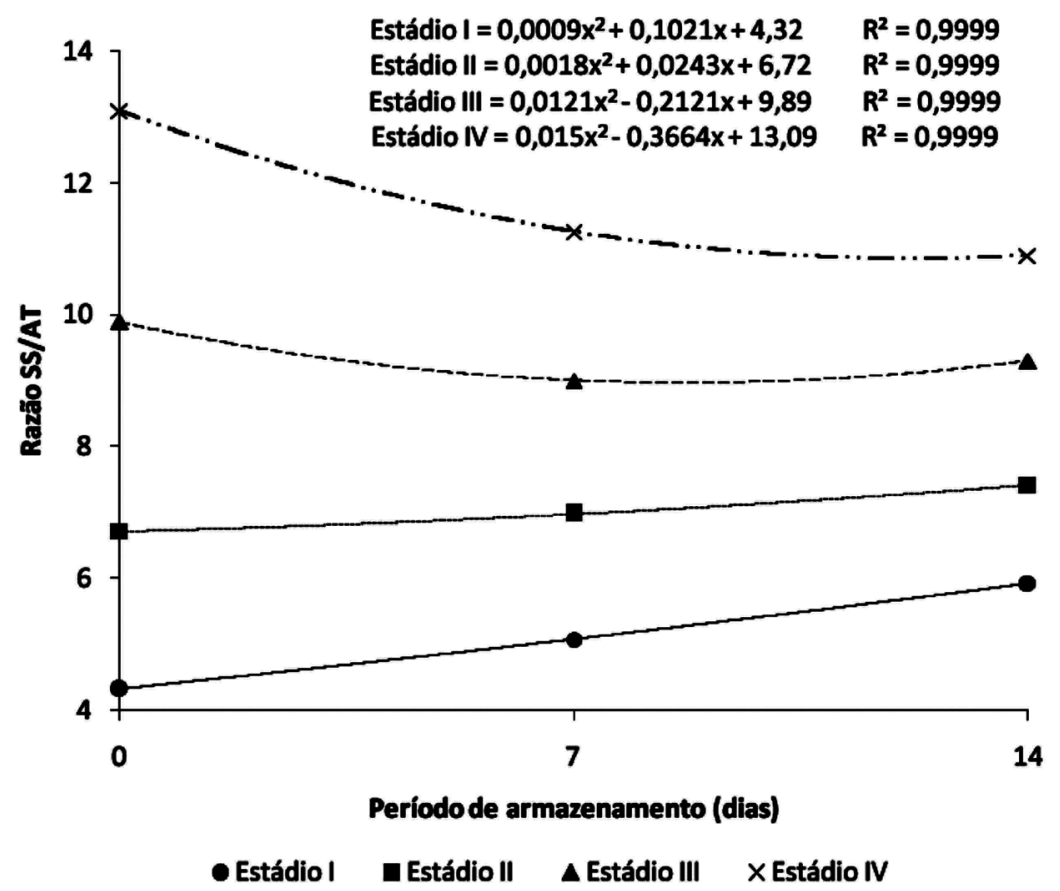

FIGURA 4 - Razão SS/AT de frutos de cajarana nos estádios de maturação I, II, III e IV submetidos à refrigeração durante o período de armazenamento. Mossoró-RN, UFERSA. 


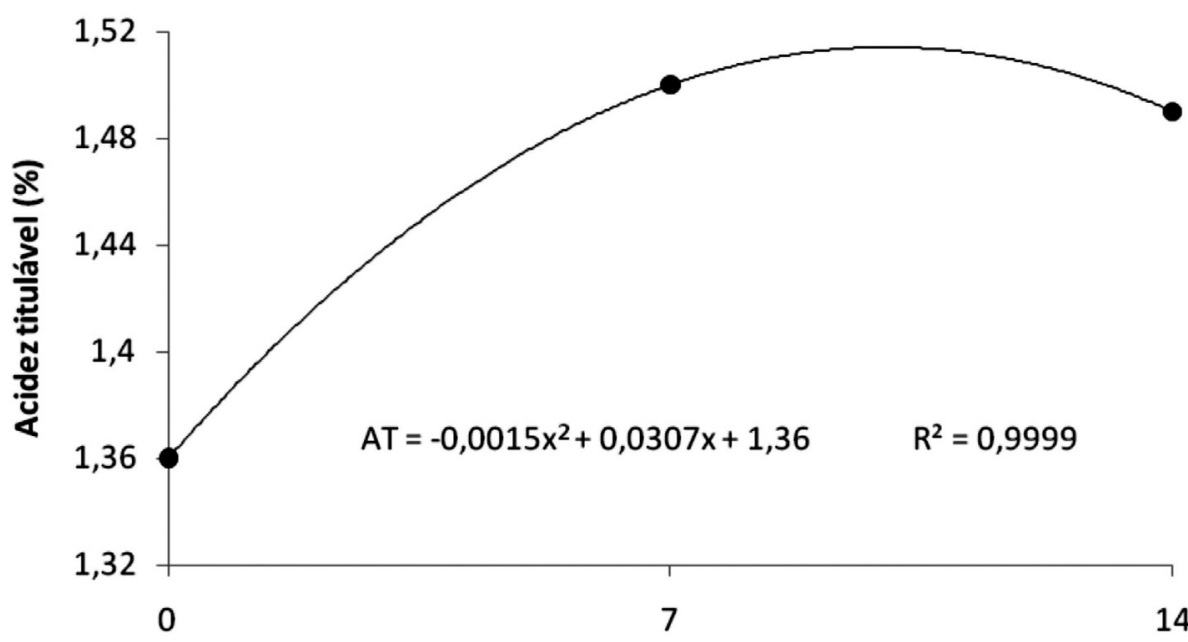

Período de armazenamento (dias)

FIGURA 5 - Acidez titulável de frutos de cajarana submetidos à refrigeração durante o período de armazenamento. Mossoró-RN, UFERSA.

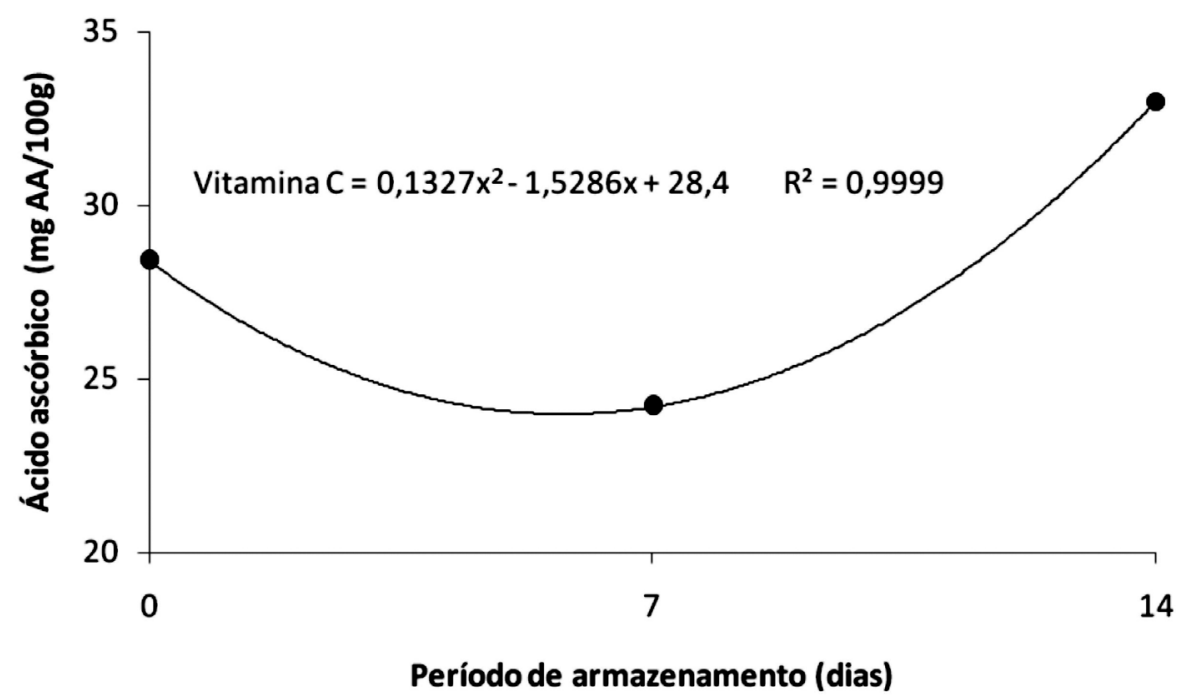

FIGURA 6 - Teor de ácido ascórbico de frutos de cajarana submetidos à refrigeração durante o período de armazenamento. Mossoró-RN, UFERSA. 


\section{CONCLUSÃO}

O armazenamento a $10{ }^{\circ} \mathrm{C}$ durante sete dias conserva as características dos frutos, independentemente do estádio de maturação. Aos 14 dias de armazenamento, apenas os frutos colhidos no estádio II de maturação mantêm características desejáveis para o consumo. Os frutos no estádio de maturação I não desenvolvem as características típicas do fruto maduro, e aqueles colhidos no estádio III e IV manifestam sintomas de injúria pelo frio.

\section{REFERÊNCIAS}

BLEINROTH, E.W.; SIGRIST, J.M.M.; ARDITO, E.F.G.; CASTRO, J.V.; SPAGNOL, W.A.; NEVES FILHO, L.C. Tecnologia de pós-colheita de frutas tropicais. Campinas: ITAL, 1992. 203p. (Manual Técnico, 9).

CARMO FILHO, F.; OLIVEIRA, O.F. Mossoró: um município do semi-árido nordestino, caracterização climática e aspecto florístico. Mossoró: ESAM, 1995. 62 p. (Coleção Mossoroense, série B).

CARVALHO, P.C.L.; RITZINGER, R.; SOARES FILHO, W.S.; LEDO, C.A.S. Características morfológicas, físicas e químicas de frutos de populações de umbu-cajazeira no Estado da Bahia. Revista Brasileira de Fruticultura, Jaboticabal, n. 30, v. 1, p. 140-147, 2008.

CHITARRA, M.I.F, CHITARRA, A.B. Pós-colheita de frutos e hortaliças: fisiologia e manuseio. 2.ed. Lavras: Editora UFLA, 2005.

DREHMER, A.M.F.; AMARANTE, C.V.T. Conservação pós-colheita de frutos de araçá-vermelho em função do estádio de maturação e temperatura de armazenamento. Revista Brasileira de Fruticultura, Jaboticabal, v. 30, n. 2, p. 322-326, 2008.

FERREIRA, D. F. SISVAR 4.3: sistema de análises estatísticas. Lavras: DEX/UFLA, 2003.

GRAHAM, O. S., WICKHAM, L. D., MOHAMMED, M. Growth, development and quality attributes of miniature golden apple fruit (Spondias cytherea Sonn). Journal of Food, Agriculture \& Environment, Helsinki, v. 2, n. 1, p. 90-94, 2004.
LIMA, E.D.P.A.; LIMA, C.A.A.; ALDRIGUE, M.L.;GORDIM, P.J.S. Caracterização física e química dos frutos da umbu-cajazeira (Spondias spp.) em cinco estádios de maturação, da polpa congelada e de néctar. Revista Brasileira de Fruticultura, Jaboticabal, v. 24, n. 2, p. 338-343, 2002.

LIMA, M.A.C.; TRINDADE, D.C.G.; SANTOS, A.C.N.; PAES, P.C. Armazenamento refrigerado de manga 'Tommy Atkins' sob atmosfera modificada (SmartbagTM). In: CONGRESO IBEROAMERICANO DE TECNOLOGÍA POSTCOSECHA Y AGROEXPORTACIONES, 5., 2007, Cartagena. Artigos completos... Cartagena: GPR/AITEP, 2007. p.1.288-1.296.

LOPÉZ, A.P.; VELOZ, C.S.; GALARZA, M.L.A./ LUÁ, A.M. Efecto del grado de madurez en la calidad y vida postcosecha de ciruela mexicana (spondias purpúrea L.). Revista Fitotecnia Mexicana, Nuevo León, v. 27, n. 2, p. 133-139, 2004.

MACIEL, M.I.S.; SILVA, W.S.; SOUZA, K.A.; MELO, E.A.; LIMA, V.L.A.G.; PEDROSA, E.M.R. Modificações pós-colheitas em frutos de 16 genótipos de aceroleira armazenados sob refrigeração. Revista Brasileira de Ciências Agrárias, Recife, v. 3, n. 2, p. 157-163, 2008 .

MARTINS, L.P.; SILVA, S.M.; ALVES, R.E.; FILGUEIRAS, H.A.C. Fisiologia do dano pelo frio em ciriguela (Spondias purpurea L.). Revista Brasileira de Fruticultura, Jaboticabal, v. 25, n. 1, p. 23-26, 2003.

MATA, M.E.R.M.C.; DUARTE, M.E.M.; ZANINI, H.L.H.T. Calor específico e densidade da polpa de cajá (Spondias lutea L.) com diferentes concentrações de sólidos solúveis sob baixas temperaturas. Engenharia Agrícola, Jaboticabal, v. 25, n. 2, p. 488-498, 2005.

MATTIETTO, R.A.; LOPES, A.S.; MENEZES, H.C. Estabilidade do néctar misto de cajá e umbu. Ciência e Tecnologia de Alimentos, Campinas, v. 27, n. 3 , p. 156-463, 2007.

MEDEIROS, A.D. Caracterização dos estádios de maturação do fruto de cajarana (Spondias sp.). 2005. 30 f. Monografia (Trabalho de Graduação) - Escola Superior de Agricultura de Mossoró, Mossoró, 2005. 
MILLER, A.; SCHAAL, B. Domestication of a mesoamerican cultivated fruit tree, Spondias purpurea. Proceeding of the National Academy of Science of the United States of America, Cambridge, v. 102, n. 1, p. 12.801-12.806, 2005.

SAMPAIO, S.A.; BORA, P.S.; HOLSCHUH, H.J.; SILVA, S.M. Postharvest respiratory activity and changes in some chemical constituents during maturation of yellow mombin (Spondias mombin) fruit. Ciência e Tecnologia de Alimentos, Campinas, v. 27, n. 3, p. 511-515, 2007.

SILVA, G.G.; MORAES, P.L.D.; ROCHA, R.H.C.; SANTOS, E.C..; SARMENTO, J.D.A. Caracterização do fruto da cajaraneira em diferentes estádios de maturação. Revista Brasileira de Produtos Agroindustriais, Campina Grande, v.11, n.2, p.159163, 2009.
SILVA, M.G.; AMORIM, S.M.C. Estresse salino em plantas de Spondias tuberosa Arruda (Câmara) colonizadas com fungos micorrízicos arbusculares. Revista Caatinga, Mossoró, v. 22, n. 2, p .91-96, 2009.

SILVA, P.R. Uma abordagem sobre o mercado de hortaliças minimamente procesadas. Informações Economicas, São Paulo v. 38, n. 4, p. 52-57, 2008.

SOUZA, A.A.; BRUNO, R.L.A.; LOPES, K.P.; CARDOSO, G.D.; PEREIRA, W.E.; CAZÉ FILHO, J. Semillas de Spondias tuberosa oriundas de frutos consechados en cuatro estadios de maturacíon y almacenadas. Revista Brasileira de Engenharia Agrícola e Ambiental, Campina Grande, v. 9, n. 3, p. 372-378, 2005.

SOARES, E.B.; GOMES, R.L.F.; CARNEIRO, J.G.M.; NASCIMENTO, F.N.; SILVA, I.C.V.; COSTA, J.C.L. Caracterização física e química de frutos de cajazeira. Revista Brasileira de Fruticultura, Jaboticabal, v.28, n.3, p.518-519, 2006. 